Revista de la red interuniversitaria de estudios sobre las literaturas rioplatenses contemporáneas en Francia

9 | 2013

Homenaje a Ana María Barrenechea

\title{
Kamtchatka literaria
}

\author{
Maya González-Roux
}

\section{OpenEdition}

\section{Journals}

\section{Edición electrónica}

URL: http://journals.openedition.org/lirico/1202

DOI: 10.4000/lirico.1202

ISSN: 2262-8339

Editor

Réseau interuniversitaire d'étude des littératures contemporaines du Río de la Plata

\section{Referencia electrónica}

Maya González-Roux, « Kamtchatka literaria », Cuadernos LIRICO [En línea], 9 | 2013, Publicado el 01

septiembre 2013, consultado el 22 septiembre 2020. URL : http://journals.openedition.org/lirico/1202 ; DOI : https://doi.org/10.4000/lirico.1202

Este documento fue generado automáticamente el 22 septiembre 2020

\section{cc) (i) (2)}

Cuadernos LIRICO está distribuido bajo una Licencia Creative Commons Atribución-NoComercialSinDerivar 4.0 Internacional. 


\title{
Kamtchatka literaria
}

\author{
Maya González-Roux
}

\section{REFERENCIA}

Fernando Aínsa, Palabras nómadas. Nueva cartografía de la pertenencia, Madrid, Iberoamericana Editorial Vervuert, 2012, 219 p. 
Ese "kiosco bizarro pero coqueto $\mathrm{y}$ misterioso", ese "extremo de una lengua de tierra considerada inhabitable" en el que -como se lamentaba Sainte-Beuve hacia 1862- Baudelaire había decidido instalarse era una tierra de asilo que el mismo crítico llamó "la Kamtchatka romántica". ${ }^{1}$ Hacia esos confines se extiende la narrativa latinoamericana, 150 años después, como revela Fernando Aínsa en su último libro, Palabras nómadas. Nueva cartografía de la pertenencia, reverberación de todos sus trabajos anteriores y en particular de Identidad cultural de Iberoamérica en su narrativa (1986), Pasarelas. Letras entre dos mundos (2002) y "Discurso identitario y discurso literario en América Latina” (2010).

El libro, como explica hacia el final la extensa introducción, aborda "la nueva

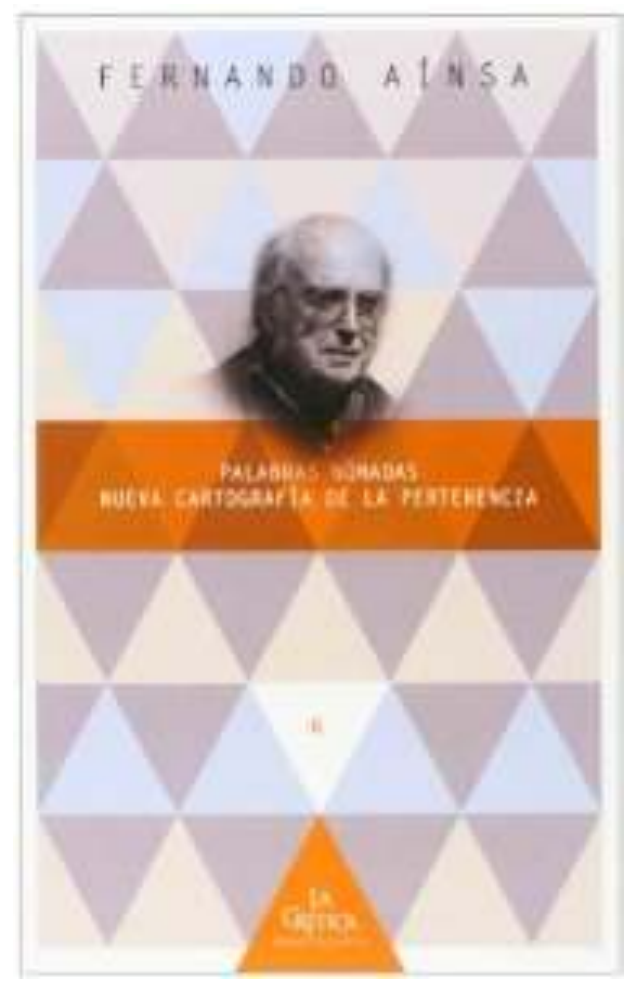
realidad transnacional" de la narrativa latinoamericana a través de sus “intercambios, diálogos, cruzamientos, aperturas y mestizajes" (62). Luego de una propuesta tan ambiciosa -se analizan más de cien obras literarias- es llamativo no encontrar un índice onomástico, herramienta esencial para un trabajo de esta envergadura. Quizás su ausencia pueda deberse al propósito del libro: trazar cartografías nómades donde las relaciones y correlaciones sean abiertas y diversas, tal como sostiene Kenneth White en L'Esprit nomade ${ }^{2}$, poeta y ensayista que Aínsa conoce bien y que ha citado con frecuencia. El nómade es aquél que abandona la autopista de la historia para ahondar en un paisaje desprovisto de todo trazado, de caminos o senderos ; el nómade debe inventarse una geografía o -concepto acuñado por Whiteuna geopoética. ${ }^{3}$ A esta invención se consagra el autor de Palabras nómades.

3 A lo largo de la introducción el ensayista traza y marca el terreno de la materia crítica que desarrollará en los capítulos siguientes. El primer corte, seco y neto, son las fechas : 1980-2012, una demarcación arbitraria que Aínsa se verá obligado a desbordar en varios momentos del libro. El revisionismo al que se aboca lo conduce a ver con cierta desconfianza las proclamas de los años sesenta y a comentar, tal vez con un tono desilusionado pero ciertamente crítico, la supervivencia de algunos escritores "que opinan de todo y escriben sobre todo con seguridad y pocas dudas" : Mario Vargas Llosa y Carlos Fuentes ("El desgaste de la literatura política"). Con la misma lógica el autor propone dos movimientos, ya desarrollados en Pasarelas, para abordar la narrativa latinoamericana: el movimiento centrípeto (las literaturas se replegarían sobre sus límites nacionales en búsqueda de expresiones que recuperen "lo tradicional", (60)) y el centrífugo (a la inversa, una buena parte de la narrativa latinoamericana, de carácter cosmopolita, "se expande y circula" sin atarse a su patria de origen, (61)).

Dentro de este nuevo panorama encuentran su lugar "nuevas" formas y temas como la introducción del lenguaje cinematográfico (Aínsa transgrede el corte temporal que él 
mismo se impuso y señala como referentes obligados a Guillermo Cabrera Infante y Manuel Puig) y musical, del melodrama y lo cursi ("La voracidad antropológica del nuevo realismo", 23-35). En esta primera parte introductoria se resaltan también las "formas breves", las propuestas transgenéricas, los "estilos discrepantes", el humor y la parodia que han ido ganando espacio en la literatura latinoamericana. Encuentran lugar en estas páginas muchos escritores, no todos necesariamente imprescindibles: Ana María Shua, David Lagmanovich, Luisa Valenzuela, Andrés Neuman, Fernando Iwasaki, Augusto Monterroso, Mario Bellatin, César Aira, Sergio Chejfec, Efraim Medina Reyes, Gloria Guardia, Daniel Sada, Ana Clavel, Guadalupe Santa Cruz, Teresa Porzecanski, Cristina Peri Rosi, Jorge Ibargüengoitia, Osvaldo Soriano, Daniel Guebel, Luisa Futoransky, Alicia Steimberg, Alicia Dujovne Ortiz, Elena Poniatowska, Alicia Borinsky, entre tantos otros. En esta nómina se confunden generaciones, estilos e influencias tal vez con el propósito de perfilar, precisamente, al "escritor transnacional y culturalmente mestizo" (49) de los capítulos posteriores.

5 El ensayo está organizado en tres partes, "Palabras nómadas", "Cartografías de la pertenencia" y "El viaje inconcluso", que pretenden dilucidar lo que son "los principios de la literatura transnacional". Para ello, Aínsa corta todas las amarras, arroja la idea de "pertenencia a un lugar" y asume el nomadismo como destino de una realidad cuyas fronteras han desaparecido (69). De ahí emana la figura del fugitivo, del nómade, del extranjero y del "artista migratorio" (76) -o las "figuras del afuera" como también las denomina retomando el concepto de Kenneth White en La Figure du dehors (1982) - que marcarían esta época de migraciones constantes y masivas. Entre las reflexiones sobre nuestra contemporaneidad se hace mención, como es de esperar, a la noción de globalización y, en ese contexto, al avance de los distintos medios de comunicación. Al resaltar la supremacía de lo actual y de lo inmediato, el ensayista apunta que "el presente se instala como permanencia" y argumenta : "Porque si hasta no hace mucho se privilegiaba el pasado, la memoria y la tradición, ahora el interés prioritario se enfoca hacia el presente."(77). Si bien es verdad que hay una generación de "nuevos escritores" que sucumben al elixir de la globalización y sus efectos, no habría que dejar de señalar que muchos otros deciden trabajar las mismas problemáticas -la memoria, la lengua y la identidad- por fuera de esta cuestión y permanecen, a pesar de ello, permeables a las "figuras del afuera". ${ }^{4}$

6 Las cartografías nómades se organizan alrededor del viaje, tópico que guía pero no estructura el estudio pues se trata justamente de proponer recorridos y abrir posibles senderos. En el caso de América Latina, el viaje tiene un carácter fundacional, su función es "constitutiva de su organicidad [de América Latina], incluso por contraste" con respecto al "espejo europeo" (69-70, idea reiterada llamativamente un poco más adelante, en la página 81). Bajo el mismo tópico, Aínsa visita brevemente el sentido inaugural que tuvo el viaje a París para las generaciones del ‘ 80 de Argentina y Chile. Lo hace para mostrar de qué modo el prestigio literario de esta ciudad se ha ido oscureciendo a lo largo de las décadas hasta llegar a degradarse en la actualidad, "porque el París que seducía hasta no hace mucho es ahora una ciudad enferma" ("El prestigio degradado de París" (97)). Pero el viaje también entraña una reconstrucción del lugar abandonado a través de la memoria, un desplazamiento que confirma el imposible regreso a la patria, a la infancia, a los orígenes o al mundo personal. Fernando Vallejo, Rodrigo Fresán, Edmundo Paz Soldán, Santiago Roncagliolo, Andrés Neumann, Consuelo Triviño, Dante Liano, Alfredo Pita, Abilio Estévez, Reinaldo Arenas, Tununa Mercado, Sylvia Larrañaga, son sólo algunos escritores que han evocado estos 
distintos regresos, como explica Aínsa en las secciones "La patria a la distancia" y "El imposible regreso".

7 El alejamiento de la patria revela diversas formas de nostalgia analizadas por Aínsa. Sin embargo, la distancia puede ser también fecunda y ofrecer cierto placer recóndito, como recordaba José Donoso : "Lo importante es no olvidar que todo escritor debe ser en parte marginal. [...]. Desde la marginalidad el mundo se ve de otra manera." (135). Llevar su propia ciudad a cuestas, como sugerían los versos de Constantino Cavafis que cita Aínsa ${ }^{5}$, supone desbordar las categorías, hoy irrisorias, "de literatura de 'dentro' y 'fuera', nacional y de 'emigración' y/o exilio" (137). En palabras del ensayista, esto supone aceptar otras formas posibles de universalidad donde el escritor sumergido en una nueva realidad percibe y recrea su mundo, su ciudad, desde una perspectiva distinta. Aínsa propone, como ejemplos de recreaciones deslocalizadas, los relatos de En la zona de Juan José Saer y el trabajo con su propia lengua que realiza Guillermo Cabrera Infante desde la distancia.

8 Las cartografías re-corren otros viajes -el sentido del viaje a Europa se retoma, más en extenso, a través de la obra de Eugenio Cambaceres, Ricardo Güiraldes, Manuel Gálvez y Julio Cortázar en el capítulo "El viaje iniciático en la tradición literaria latinoamericana"- y otras fugas que subrayan la marginalidad y la periferia como una muestra de este "repliegue sobre sí mismo" y de esta salida "del gran cauce" (196). De este exilio interior, según Aínsa, proviene "el auge de un individualismo negativo de signo diferente al individualismo ensalzado por la cultura occidental". La narrativa de Enrique Vila-Matas, el "extranjero vocacional", "el más latinoamericano de los escritores españoles" (197), conocido epígono de Borges y Pessoa, ilumina estas nuevas constelaciones literarias donde "coexisten en forma poligenérica el ensayo, la crónica, la novela y ese género híbrido ahora reivindicado con ironía por muchos autores : la autoficción." (198).

9 Resulta particularmente interesante el capítulo dedicado a los "nuevos repertorios de la identidad". Si el individuo se encuentra siempre en una simultaneidad de círculos (familiar, individual, étnico, religioso, político, profesional), su identidad se "desplaza y se abre en ese espacio circular" : "Mientras que el círculo de pertenencia tiene nostalgia de lo monocultural y de los horizontes limitados comarcales, de las lenguas incontaminadas y de las incuestionables verdades sobre el origen, el de la apertura apuesta al intercambio y al conocimiento del otro." (112-113). Encierro sobre sí mismo y permanencia se oponen a la progresiva integración de lo nuevo, postura que encuentra apoyo en palabras de otros intelectuales como Albert Memmi y Daniel Sibony, quienes han trabajado desde esta misma perspectiva. "La identidad estaría formada por un conjunto de permanencias a través de un cambio continuo" (113), resume Aínsa e indica que estas permanencias son aún más relativas en quienes han emigrado debido, justamente, a las continuas adaptaciones. Esta nueva mirada sobre la identidad conlleva un nuevo rol para el escritor, el surgimiento de una "geografía alternativa de la pertenencia" -como lo reitera en múltiples oportunidades-, una nueva mirada que reconoce la diferencia y la alteridad (120) y una valoración de la marginalidad buscada cada vez con mayor fuerza. En palabras de Héctor Libertella : "Si Argentina es un país periférico en el mundo, su escritor más periférico será entonces centralmente argentino. A mí me ha costado mucho sostener esta paradoja... ¡Cuánto más marginal, más central !" (“La pérdida de los referentes nacionales" (130)). 
Esta cartografía que nos ofrece Fernando Aínsa lleva consigo el sentido de las escrituras anteriores del autor. Parafraseando a Cavafis, el lector no encontrará nuevas perspectivas en estas Palabras ya que ellas vagan por las mismas calles y barrios que Aínsa nos hizo descubrir y que despertaron tanto interés entre los críticos. Sin embargo, siempre es sugestivo tener noticias de estos confines y viajar hacia la Kamtchatka literaria.

\section{NOTAS}

1. C. Roy, "Préface", Charles Baudelaire. Euvres complètes, Paris : Éditions Robert Laffont, 2011, p. IV. Cf. C. Baudelaire, “À Sainte-Beuve”, ibid., p. 927-928.

2. "[Le désir de savoir de ces pages est diffus, dispersé et] c'est pour cela qu'il est question d'esprit nomade, et de cartographie : de (nouvelles) co-ordonnées, de (nouvelles) corrélations, de liaisons diverses et parfois, sans doute, dangereuses.", K. White, L'Esprit nomade, Paris : Editions Grasset \& Fasquelle, 1987, p. 11.

3. Ibid., p. 11.

4. Cf. S. Molloy y M. Siskind (eds.), Poéticas de la distancia. Adentro y afuera de la literatura argentina, Buenos Aires: Grupo Editorial Norma, 2006. En este libro participan María Negroni, Marcelo Cohen, Diana Bellessi, Edgardo Cozarinsky, Mercedes Roffé, Alicia Borinsky, Sergio Chejfec, Luisa Futoransky, Tamara Kamenszain, Martín Kohan, Alan Pauls y Luisa Valenzuela.

5. “Dijiste : 'Iré a otra tierra, iré a otro mar./ Otra ciudad ha de haber mejor que ésta' [...] No hallarás nuevas tierras, no hallarás otros mares./ La ciudad te seguirá. Vagarás por las mismas / calles. Y en los mismos barrios te harás viejo ; / y entre las mismas paredes irás encaneciendo. / siempre llegarás a esta ciudad. Para otra tierra -no lo esperes- no tienes barco, no hay camino.", p. 136.

\section{AUTORES}

\section{MAYA GONZÁLEZ-ROUX}

Université Paris Est Marne-la-Vallée 